\title{
Causas criminales contra el Lic. Don Teodosio Lares, ex ministro de Justicia, Negocios Eclesiásticos e Instrucción Pública y ex secretario de Despacho del gobierno dictatorial de Antonio López de Santa Anna. 1856-1857
}

\section{Martín Escobedo Delgado}

UNIVERSIDAD AUTÓNOMA DE ZACATECAS, mescobedo07@hotmail.com

\section{Presentación}

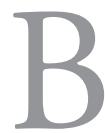

uena parte del siglo XIX mexicano es concebida como una etapa donde imperaron el caos y la incertidumbre. Tras la crisis política de la monarquía española que significó a la postre su disolución y el nacimiento de Estados libres y soberanos en América, éstos caminaron en lo sucesivo utilizando sus propios medios. En México, luego del fallido Primer Imperio, se asomaron muy pronto distintos proyectos de nación. El que obtuvo un fulgurante $\mathrm{e}$ inicial triunfo fue el republicano que se mantuvo vigente en el lapso que abarcó de 1824 a 1835. Agotado por luchas intestinas, un gobierno central disminuido, arcas nacionales permanentemente menguadas, entidades federativas poderosas por el control que ejercían de su fiscalidad, gobiernos centrales breves y sin continuidad, descontento creciente y una decepción que se generalizaba, el proyecto republicano periclitó para dar paso a las Siete Leyes (1836) y más tarde a la vigencia de las Bases Orgánicas (1843). ${ }^{1}$ Los enfrentamientos entre diversas facciones políticas y militares continuaron, incluso tras la promulgación de la Constitución liberal de 1857. La agita-

${ }^{1}$ Véase José Antonio Serrano Ortega, "Epílogo. La república federal desde los estados, 1824-1835”, en Práctica y fracaso del primer federalismo mexicano (1824-1835), coord. Josefina Zoraida Vázquez y José Antonio Serrano Ortega, 595-609 (México: El Colegio de México, 2012). 
ción y la inestabilidad política prevalecientes dieron lugar a la intervención francesa y a la posterior instauración del Segundo Imperio.

No obstante al característico desconcierto que predominó durante buena parte del ochocientos mexicano, existieron personajes que lucharon contra viento y marea por restablecer el orden y la legalidad. En este sentido, una figura singular que empeñó sus afanes para instalar la paz, el progreso y el imperio de la ley en el país, fue sin lugar a dudas, don Teodosio Lares.

A pesar de que don Teodosio Lares es considerado por la historiografía liberal "el jurista maldito", recientemente varios estudiosos se han encargado de abordar su vida y su obra. ${ }^{2}$ Nacido en Asientos en el año de 1806, cuando esta localidad pertenecía a la Intendencia de Zacatecas, Teodosio Lares creció abrazando la fe católica y formándose con esmero en el ámbito académico. Estudió en Guadalajara la carrera de abogado y, una vez obtenido el título, se enroló en el Tribunal Superior de Justicia del Estado de Zacatecas desempeñando diversos cargos. Sin abandonar sus labores como jurista, más tarde trabajó como profesor y director en la Casa de Estudios de Jerez, centro que se transformó en Instituto Literario de Zacatecas con sede en la capital del estado, donde siguió fungiendo como catedrático y director hasta $1848 .{ }^{3}$ Justo en este año fue elegido diputado

\footnotetext{
${ }^{2}$ Vela Latrice Lynn, Political career of Teodosio Lares, 1848-1867 (Tesis doctoral, The University of Texas at Austin, 1951); Florence Toussaint, Teodosio Lares (México: Senado de la República, 1984); Francisco Wiechers, Teodosio Lares, un jurista del siglo XIX (México: Suprema Corte de Justicia de la Nación, 2006); Jesús Antonio de la Torre, Teodosio Lares: Nuestro jurista maldito (Aguascalientes: Poder Judicial del Estado de Aguascalientes, 2007); José Luis Acevedo, Justicia e instrucción pública a través de la obra de Teodosio Lares, 1806-1870 (México: Taberna Libraria Editores, 2015); Andrés Lira, "El contencioso administrativo y el Poder Judicial en México a mediados del siglo XIx. Notas sobre la obra de Teodosio Lares", en Memoria del II Congreso de Historia del Derecho Mexicano (México, Universidad Nacional Autónoma de México, 1981), 621-634; del mismo Andrés Lira, "Orden público y jurisdicción en el siglo XIx. El contencioso administrativo español visto desde el constitucionalismo mexicano”, Istor (16) (2004): 195-206; Martín Escobedo Delgado, "El conservadurismo militante. Teodosio Lares: la tradición monárquica como alternativa política”, en Medrar para sobrevivir. Individualidades presas en la trama de la historia (siglos XVI-XIX), Thomas Calvo y Armando Hernández, 123-152 (México: El Colegio de San Luis, 2016).

${ }^{3}$ Como catedrático y director del Instituto Literario de Zacatecas, Teodosio Lares destacó palmariamente innovando en el método de enseñanza, elaborando libros de
} 
por Zacatecas al Congreso General, por lo que condujo sus pasos hacia la Ciudad de México, donde, en lo sucesivo, figuraría en el plano nacional. En 1850 ocupó una curul en el Senado de la República, más tarde fue nombrado ministro de Justicia, Negocios Eclesiásticos e Instrucción Pública en el gobierno de Antonio López de Santa Anna (1853-1855). Luego del fallecimiento del Lucas Alamán -principal consejero de la presidencia-, Lares se convirtió en el brazo derecho del Seductor de la patria. En el régimen santanista el licenciado Lares desarrolló una febril actividad: dictó conferencias, escribió en diferentes diarios, compiló y publicó materiales jurídicos, promulgó numerosas leyes, atendió su ministerio y asesoró al presidente en asuntos legales. El Plan de Ayutla provocó la caída de Santa Anna en 1855. Sin un sostén en el poder, Teodosio Lares fue enjuiciado por considerársele cómplice de las tropelías cometidas por el caudillo veracruzano.

Los documentos que aquí se presentan son justamente dos procesos judiciales que se le fincaron al licenciado Lares después del derrocamiento de Santa Anna. Su importancia radica no sólo en que muestran las vicisitudes de la justicia mexicana en este complicado lapso del mediodía de la centuria decimonónica, sino, sobre todo, en las instancias que se involucran y los modos en que éstas se relacionan: el Ayuntamiento del puerto jarocho, el gobernador de Veracruz, la Suprema Corte de Justicia de la Nación, el Ministerio de Justicia, el Congreso Extraordinario Constituyente y hasta el presidente de la República. Como telón de fondo, los documento también muestran las relaciones existentes entre los Poderes de la Unión, así como los acontecimientos que complicaron aún más el panorama de este lapso: el Tratado de Guadalupe-Hidalgo, la invasión estadounidense, el Tratado de La Mesilla y la amenaza francesa que se cernía sobre la debilitada y mutilada República mexicana.

texto que fueron adoptados por otros institutos del país y diseñando y operando un plan de estudios moderno que sirvió de modelo a otras escuelas similares. Véase Rosalina Ríos Zúniga, "La creación de un Plan de Estudios Moderno en el Instituto Literario de Zacatecas (1832-1854)", en Universidad y sociedad en Hispanoamérica: grupos de poder, siglos XVIII y XIX, comp. Margarita Menegus, 355-389 (México: CESu-unam, Plaza y Valdés Editores, 2001). 
En los documentos, a don Teodosio Lares se le imputan nutridos delitos, como ser el responsable del Tratado de La Mesilla y quedarse con una parte del dinero pagado por los Estados Unidos como indemnización; haber autorizado al gobierno estadounidense a no cumplir con las obligaciones contraídas en el Tratado de Guadalupe-Hidalgo; autorizar al ejército de la nación a cometer diversas crueldades en los estados de Guerrero, México y Michoacán con el objeto de reducir a los sublevados que enarbolaron el Plan de Ayutla; haber adelantado dos años de sueldo a un ministro sin que éste haya desempeñado labor alguna; ordenar el traslado de indígenas yucatecos a trabajar en condiciones de trabajo forzado a un país extranjero; y, finalmente, se le acusó de ordenar el despojo del que fue objeto el Ayuntamiento de Veracruz por algunos particulares.

Como se advierte en los documentos, el juicio se suspendió en 1857 debido a que el país se enfrascó en otro episodio bélico porque en ese año un grupo de políticos y militares se opuso a la aplicación de la recién promulgada Constitución; en consecuencia, Benito Juárez desconoció a Comonfort como titular del Ejecutivo y se autoproclamó presidente de la República, esto inició la guerra de Reforma que arrastró nuevamente al país a la confusión y al desconcierto. En el río revuelto de la patria, Lares sacó provecho, pues, al encontrarse el país en vilo, los tribunales judiciales que llevaban los juicios contra el abogado suspendieron actividades, lo que produjo una distracción cercana al olvido, pues, en plena guerra de Reforma, Lares fungió como ministro del presidente interino Miguel Miramón (1859), y en la siguiente década ejerció la titularidad del Ministerio de Justicia, desempenándose de manera simultánea como presidente del Consejo de Ministros durante el Segundo Imperio. Encumbrado en las más altas esferas del poder, las instancias judiciales desecharon el juicio que años atrás levantaron contra este controvertido personaje.

Los materiales en cuestión son inéditos. Se resguardan en la Colección Latinoamericana Nettie Lee Benson de la Universidad de Texas en Austin. Están ubicados en la Colección García de la serie “Teodosio Lares papers, 1856-1857”. Los dos juicios suman 28 fojas: el primero 19 y el segundo 9. En casi todas las fojas aparecen tres 
sellos en los márgenes que a la letra dicen: "Garcia Collection. The University of Texas", "LARES" y "GARCIA. TxU”. En esta transcripción se suprimieron cuestiones mínimas que son repetitivas y que se refieren a los mismos procesos. Se decidió integrar los dos juicios porque fueron los únicos que se le siguieron a don Teodosio Lares en los ańos posteriores a la caída definitiva de Santa Anna. Pero también porque lo asentado en ellos influyó para que la vituperada imagen de este personaje trascendiera en el tiempo, a tal grado que hoy el himno del estado de Aguascalientes califica de nefasto y traidor a Lares, individuo que no merece el perdón de esa entidad. No cabe duda que documentos como éstos, ubicados en contexto, podrán proporcionar nuevas lecturas y nuevas interpretaciones al complicado y paradójico siglo XIX mexicano.

\section{Documento}

Suprema Corte de Justicia, año de 1857.

Sobre la responsabilidad que resulta al Sr. Licenciado Dn. Teodosio Lares como Secretario del Despacho en la época de la última dictadura del Señor Don Antonio López de Santa Anna.

Cuaderno principal núm. 1. Registro criminal de la 2a Sala núm. 9, folio 23.

Secretario Aguilar.

Julio 4 de 1857

Comuníquese al Exmo. Sr. Gobernador del Distrito, que Dn. Teodosio Lares se ha presentado a esta Suprema Corte de Justicia, a cuya disposición lo ha puesto el Gobierno Supremo. Notifíquese al expresado Sr. Lares permanezca en su casa en clase de detenido a disposición de esta Segunda Sala, y procédase a tomarle su declaración preparatoria.

En el mismo día, presente en su casa el Sr. Teodosio Lares, le hice saber el supremo decreto anterior, y entendido dijo lo oyó, y lo firmó. Doy fe. Natera. 
En siete del mismo presente, el Sr. Dn. Teodosio Lares protestó decir verdad en lo que supiere y fuere preguntado, y siéndolo por sus generales dijo: que se llama como queda dicho, de edad de cincuenta y un ańos, casado, de ejercicio abogado de los Tribunales de la República, natural del Estado de Zacatecas.

Preguntado si cuando fue Secretario del Despacho y Ministro de Justicia en la administración de Dn. Antonio López de Santa Anna aprobó el tratado celebrado con los Estados Unidos de América, el día 30 de diciembre de 1853, y sancionado, previas las correspondientes ratificaciones el día 20 de julio de 1854, o se opuso al ajuste de dicho Tratado conocido vulgarmente con el nombre de $L a$ Mesilla, y si dictó o autorizó con su firma algunas órdenes dirigidas a su ejecución en la parte que por él se enajenó una porción del territorio nacional, dijo: que el que habla no puede responder sino de sus propios actos y que el punto sobre que se le pregunta, no pasó por su respectivo Ministerio. Nada puede por lo mismo decir de él, ni de su incumbencia ha sido dictar órdenes para la ejecución del tratado sobre que se le pregunta.

Preguntado si aprobó o se opuso a que dicho Tratado se concluyera sin la previa notificación del Consejo de Estado, dijo: que se refiere a lo que tiene dicho en la pregunta anterior, por no ser este negocio de su ramo.

Preguntado sobre si aprobó o se opuso a que en dicho Tratado se declarara libre al gobierno de los Estados Unidos de las obligaciones que había contraído en el artículo 11 del de Guadalupe-Hidalgo celebrado el día 2 de febrero de 1858 y sancionado el 3 de mayo del mismo año, o si dictó o autorizó con su firma algunas órdenes relativas a la ejecución del Tratado de 1854, en la parte que revocó lo estipulado en el artículo 11 del de 1848, dijo: que siendo el punto sobre el que se le pregunta relativo al contenido del Tratado cuyo negocio no fue de su Ministerio, se refiere a lo que tiene dicho.

Preguntado si el negocio del tratado de La Mesilla, no se discutió en Junta de Ministros, y cuál fue en ese caso su voto, acerca de los tres puntos a que se refieren las anteriores preguntas, dijo: que en lo relativo a lo que pasaba en la Junta de Ministros, como se hacía bajo la confianza y secreto natural del hombre, nada puede responder. 
Instado para que conteste categóricamente sobre si el Tratado de La Mesilla se trató o no en la Junta de Ministros y cuál fue su voto en ese negocio, apercibido de lo que hubiere lugar en derecho, si no se prestare a responder, dijo: que no pudiendo responder en lo relativo a Junta de Ministros, sin violar el secreto natural bajo el cual pasan los negocios que allá se tratan, se refiere a lo que tiene dicho.

Instado de nuevo a que contestase bajo el apercibimiento que se le ha hecho, en atención a que la pregunta se refiere a hechos propios en los que no procede la obligación de guardar secreto, dijo: que por la razón que tiene expuesta, cree que no puede contestar otra cosa.

Preguntado sobre si cuando se celebró el Tratado no estimó de su deber consultar al Jefe de Gobierno que no ratificara las estipulaciones relativas a la venta de parte del territorio nacional, y a la revocación del artículo 11 del de Guadalupe Hidalgo así como que no se concluyera el de 1854 sin la previa notificación del Consejo de Estado; y si estimando que era su deber, consultó así al jefe de la administración; dijo: que los negocios a los que se refiere la pregunta son ajenos de su Ministerio; por lo mismo acerca de ellos y formalidades con que se hicieron, nada tiene que responder.

Preguntado sobre si aprobó o se opuso a que Dn. Antonio López de Santa Anna aplicara a su persona una parte de la indemnización pecuniaria que el gobierno de los Estados Unidos dio en virtud del referido Tratado de La Mesilla; si dictó o autorizó con su firma alguna orden para que se hiciera tal aplicación, dijo: que no tiene noticia de que se haya hecho semejante aplicación.

Preguntado si no se trató en Junta de Ministros el punto sobre que acaba de ser interrogado, y cuál fue en él su voto; dijo: que en cuanto a lo relativo a la Junta Ministros se refiere a lo que tiene dicho.

Preguntado sobre si aprobó o se opuso a que por medio de contratos se sacaran del Estado de Yucatán familias indígenas, y se les llevara a trabajar forzadamente en un clima mortífero en país extranjero, o si dictó o autorizó con su firma algunas órdenes relativas a la ejecución de esos actos, dijo: que no habiéndose girado por su Ministerio el negocio sobre que se le pregunta, nada tiene que responder acerca de él. 
Preguntado sobre si aprobó o se opuso a que en la guerra que se hizo en los Estados de Guerrero, México y Michoacán se mandaran talar e incendiar, pueblos y cometer otras crueldades, o dictó o autorizó con su firma algunas órdenes que tuvieran por objeto la ejecución de actos de esa clase, dijo: que los negocios relativos a la guerra y órdenes que se hallan dictado, no pasaron ni se dictaron por el Ministerio de su cargo; y por lo mismo acerca de esto nada tiene que responder.

Preguntado sobre la extracción de familias indígenas del Estado de Yucatán y providencias dictadas sobre el modo de hacer la guerra en los de Guerrero, México y Michoacán, se discutieron en la Junta de Ministros y cuál fue en su caso su voto, dijo: que en lo relativo a Junta de Ministros se refiere a lo que tiene dicho.

Instado para que conteste categóricamente sobre sus votos acerca de la distribución que se dio a la indemnización pecuniaria de $\mathrm{La} \mathrm{Me-}$ silla, extracción de indígenas del Estado de Yucatán y crueldades cometidas en la guerra de los de México, Guerrero y Michoacán, en atención a que el deber a que se acoge, no se extiende a hechos propios; apercibido de lo que hubiere lugar en derecho, si se resistiere a contestar dijo: que se refiere a lo que sobre el particular tiene contestado.

Preguntado si no creyó deber consultar al jefe de la administración que no se aplicara parte del precio de La Mesilla, que no permitiera la extracción de familias indígenas de Yucatán, y que no se hiciera la guerra en los Estados de Guerrero, México y Michoacán, de la manera cruel que se llevaba a cabo, y si lo hizo así, dijo: que siendo los negocios sobre que se versa la pregunta algunos de los ramos de que estaba encargado, se refiere a lo que tiene dicho.

Preguntado sobre si aprobó el acuerdo del 8 de agosto de 1855, en que se autorizó el declarante al Sr. Dn. Ignacio Aguilar, dos años de licencia para no desempeñar sus Magistraturas en el Supremo Tribunal de Justicia, con permiso de ejercer la abogacía, y abonándoselos el sueldo adelantado correspondiente al expresado periodo, dijo: que le parece que este punto no puede tratarse en este juicio; pero que por vía de instrucción dirá que con la misma fecha del acuerdo a que se refiere la pregunta, se le comunico al que habla oficialmente el repetido acuerdo por la persona que hacía de Ministro en las faltas e impedimentos del propietario, según aparece de la 
nota que pone de manifiesto, y que podrá agregarse, si el Sr. Ministro que pregunta, o la Excelentísima Sala lo tuvieren por conveniente, o podrá quedar en poder del que responde para entregarlo cuando se crea conveniente.

Instado para que diga categóricamente si aprobó dicho acuerdo o se opuso a él, ha percibido de lo que hubiere lugar, si rehusare hacerlo, contestó: que no cree que el acto de que se trata sea de su responsabilidad, pues que aún entiende que por él se juzga al Ministro respectivo que en él intervino, y se refiere por lo mismo a lo que tiene dicho.

Preguntado sobre los motivos que tuvo para librar al gobierno del Estado de Veracruz la orden del 23 de junio de 1853, en que se mandó que el departamento de la ciudad del mismo nombre, devolviera a los que se decían dueños de las oficinas públicas de gobierno que fueron de Dn. Ángel de Santa Anna y de Figueroa y de Cardena, los locales de dichas oficinas, e indemnizarse a los interesados por los dańos y perjuicios que reclamaran, dijo: que haciendo más de cuatro ańos que se expidió la orden sobre que se le pregunta, no recuerda en este momento los motivos acerca de los cuales es preguntado; pero que por vía de instrucción dirá que se refiere en un todo a la constancias que obran en el Ministerio de Justicia y a la misma orden que se dice expedida, manifestando además, que según cree, el punto que se le pregunta le parece no debe corresponderse en el presente juicio.

Con lo que se suspendió esta diligencia, dejándola abierta para ampliarla en lo de adelante si fuere necesario, y leída al Sr. Lares, se afirmó y ratificó en su contenido y la firmó en unión del Sr. Ministro Semanero, por ante mí de que doy fe. Ortega. Teodosio Lares. Eulogio Barrera, oficial.

México, julio 7 de 1857.

Excelentísimo Sr. El Fiscal dice: que desde que Dn. Antonio López de Santa Anna volvió últimamente a la República, y se encargó del Poder Supremo a consecuencia de la revolución iniciada en Jalisco y consumada en esta capital, se hizo reo de traición a la Patria destruyendo el sistema de su gobierno que se había mandado sostener y respetar de la 
manera más explícita y terminante, como puede verse en el Plan y demás documentos de la época; y hollando todas las garantías sociales, todos los principios, todas las reglas y todas las costumbres del país, se erigió en el déspota más arbitrario y absoluto que se haya visto en nuestros tiempos. Posesionado de ese poder ilegal, lo ejerció por el largo periodo de veinte y siete meses y aún trató de perpetuarse en él por la cábala y la fuerza, y aún de darle vigor para después de su muerte; y sin embargo si lo hubiera empleado en bien de sus conciudadanos y en engrandecimiento de la Patria, ésta hubiera perdonado la bastardía de su origen, pero lejos de esto, la vendió traidoramente al extranjero, la entregó a las crueles manos del salvaje, se apropió sin título ni formalidad de ninguna clase de una suma considerable de sus caudales, autorizó las ventas de hijos, y derramó por todas partes el luto y la desolación con los destierros y expatriaciones de centenares de mexicanos... los patíbulos, la devastación y el incendio.

Entre los mil cómplices de que se servía este tirano, los más delincuentes sin duda, los más dignos de execración y castigo, fueron sus Ministros de Estado porque eran sus más inmediatos consejeros y sus principales ejecutores, porque con su nombre y sus influencias, sus talentos y sus trabajos granjearon al que apellidaban Gobierno Supremo de la Nación, el viso, el prestigio, la reputabilidad, y los recursos que lo habilitaron para figurar dentro y fuera del país, y consumar a su nombre la venganza el prevaricato, la depredación y demás crímenes de que ha hecho mérito. Cómplices o principales autores de la preparación, ordenación y consumación del delito, el Dictador y sus Ministros fueron igualmente responsables, sin que alguno de ellos pueda rehusar la solidaridad porque no intervino directamente en tal o cual acto de la administración, porque ellos mismos establecieron esa solidaridad en la $5^{\mathrm{a}}$ de sus bases, dadas en la ley del 22 de abril de 1853, que todos aquellos negocios que importasen una medida general que causasen gravamen a la Hacienda pública, $o$ que por su gravedad lo exigiesen a juicio del Gobierno, se tratarán en Junta de Ministros, y adoptado por el presidente el parecer de la misma junta, quedaría encargado de la ejecución el Ministerio respectivo. Desde los primeros excesos cometidos por ese llamado gobierno los beneméritos autores del Plan de Ayutla y Acapulco, llamaron al 
orden a los responsables, conminándolos con que se les trataría como enemigos de la independencia nacional; pero a esa advertencia saludable respondieron con una guerra obstinada de muerte y exterminio que prolongan hasta que agobiados por la fuerza y aterrados con la ira y la execración nacional, huyen despavoridos no sin haberse antes provisto de los caudales públicos, dejando por último crimen expuesta a la nación tan justamente resentida, sancionando como ley el Plan de Ayutla exige que sus opresores sean ejemplarmente castigados; y con razón el Gobierno Legítimo, fiel intérprete de su voluntad soberana, expidió el decreto del año próximo pasado, cuyo cumplimiento viene hoy a demandar el Fiscal ante V. E. en la persona de Dn. Teodosio Lares, Ministro que fue del Dictador Antonio López de Santa Anna, y su correo en los crímenes de su administración.

Ya esos crímenes quedan indicados y los precisa en seis capítulos el artículo 1 del citado decreto. Además, es responsable el Sr. Lares del prevaricato de que instruye el cuaderno acumulado, consistente en el despojo que hizo al Ayuntamiento de Veracruz de parte de sus bienes, por favorecer a lo que parece, a Dn. Ángel Santa Anna, hijo del Dictador, por su orden de 23 de junio de 1853, que en copia certificada corre en nueve fojas; y si el que suscribe no está equívoco, es así mismo reo de varios destierros de que debe haber constancia en la Secretaría, en una lista o expediente remitido por la Excelentísima

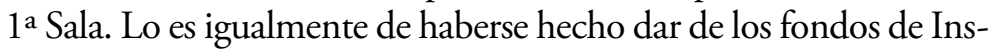
trucción o del Poder Judicial la suma de nueve mil pesos por adelanto de sueldos del empleo de Magistrado del $7^{\circ}$ Tribunal de la nación, de que no llegó a entrar en posesión, y que no podía devengar su justicia, porque a la vez se hizo otorgar dos años de licencia, proveyéndose así de fondos por esa especie de concusión cometida en el último día de su Ministerio, para huir y burlar la justicia nacional. De este hecho hay en esa Excelentísima Sala expediente separado.

Notorios los principales delitos de que se ha hecho mención, y notoria la complicidad del Sr. Lares, ha venido a dar una prueba más de su delincuencia resistiéndose a declarar en los términos que se ven en su declaración preparatoria de fojas 6 a 14 de este cuaderno, pues según lo prevenido en la parte final de la Ley $3^{a}$, artículo 13 , parte $3^{\text {a }}$, debe tenérsele por confeso de los dichos delitos. 
En vista de esto y de que ellos tienen designadas por derecho penas corporales, el Fiscal, entablando querella formal contra Dn. Teodosio Lares, pide a V. E. se sirva mandar reducir a prisión y que instruya la sumaria correspondiente, hasta ponerla en estado de tomarle su confesión con cargos; en el que, y antes de recibirla, pide así mismo este Ministerio que se le dé nueva vista.

México, julio 12 de 1857.

Por lo que resulta de lo actuado, y con arreglo al artículo 44 del Estatuto orgánico, se declara bien preso al Sr. Dn. Teodosio Lares, y en consideración a que el Sr. Ministro que le recibió su declaración preparatoria, ha informado a la Sala que cuando practicó esa diligencia, se hallaba el Sr. Lares enfermo y en la cama; se nombra a los facultativos Dn. José María Vértiz y Dn. Luis Hidalgo Carpio, para que pasen a reconocerlo y certifiquen sobre su estado; y con el resultado de esta diligencia se proveerá lo que corresponda sobre el lugar de su prisión, haciéndose saber este auto.

México, julio 13 de 1857.

En el mismo día, presente en su casa el Sr. Dn. Teodosio Lares, le hice saber el supremo auto anterior, y entendido dijo: lo oye, y que con el debido respeto dice que apela ante el Tribunal que corresponda del auto que se le notifica, en la parte en que lo declara bien preso, y firmó. Eulogio Barrera, Oficial.

El profesor de Medicina y Cirugía que suscribe. Certifica que el día 13 de corriente, por disposición de la Suprema Corte de Justicia, ha pasado a reconocer al Sr. Dn. Teodosio Lares, con el fin de decir si este seńor se halla o no enfermo; y que habiéndose informado de sus padecimientos, supo que hace algunos años padece de una manera intermitente, un dolor en el lado izquierdo del vientre, y que en la actualidad lleva dos días de tener algunas deposiciones a consecuencia de una ligera indigestión.

Luis Hidalgo Carpio.

México, julio 14 de 1857. 
El Fiscal dice: que notificado a Dn. Teodosio Lares el supremo decreto del 13 de corriente, suplicó de él en la parte que lo declara bien preso. El auto es suplicable, porque aunque interlocutorio trae gravamen irreparable en la definitiva, pero sólo en el efecto devolutivo según lo prevenido en el artículo 132 de la Ley de 23 de mayo de 1757; y en tal virtud el Fiscal pide a V. E. se sirva admitir la súplica en dicho efecto y mandar que se dirija a la Excelentísima $1^{\text {a Sala el }}$ testimonio de que habla el citado artículo; siguiendo esta causa según su estado.

México, julio 17 de 1857.

Vista la súplica interpuesta por el Sr. Dn. Teodosio Lares del auto de 13 del corriente en que se le declara bien preso, de conformidad con lo pedido por el Señor Defensor Fiscal, se declara suplicable el expresado auto en sólo el efecto devolutivo: en consecuencia, remítase

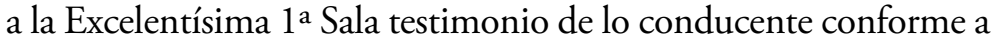
lo prevenido en el artículo 132 de la Ley de 23 de mayo de 1837; y hágase saber.

México, julio 18 de 1857.

José María Vértiz, profesor de Medicina y Cirugía. Certifico: que habiendo ido a la casa del Sr. Lic. Dn. Teodosio Lares, con el objeto de reconocerlo, según la disposición de la 2a Sala de la Suprema Corte de Justicia, lo encontré con un ataque de los que padece frecuentemente, y que consisten en dolores abdominales, meteorismo y algunas evacuaciones alvinas; acompańado todo esto de una gran postración de fuerzas. El ataque, visto aisladamente, parece de poca importancia, pero si se considera la frecuencia en que se presenta (frecuencia que me consta por haber asistido al paciente en otra época) y además que las más veces aparece sin causa apreciable; no puede menos que considerarse como una enfermedad de importancia que a mi juicio puede comprometer la vida del Sr. Lares si no la atiende seriamente. Lo que, para el uso a que haya lugar firmo.

José María Vértiz.

México, julio 25 de 1857. 
Auto de la 2a Sala de la Suprema Corte de Justicia: Diríjase oficio al Sr. facultativo Dn. Ignacio Erazo para que proceda a reconocer al Sr. Dn. Teodosio Lares, y remita a esta Sala el certificado correspondiente sobre el estado de la salud de este señor. Lo comunico a U. para los fines consiguientes, diciéndole además que el Sr. Dn. Teodosio Lares, vive en la casa número 2 de la plazuela del Salto del agua, y remitiendo a U. el papel correspondiente para que extienda el certificado.

México, julio 25 de 1857.

En cumplimiento al supremo auto de la Excelentísima $2^{\text {a Sala de la }}$ Suprema Corte de Justicia, en el que se me previene proceda a reconocer al Sr. Dn. Teodosio Lares, y remita a la citada Sala el certificado correspondiente sobre el estado de la salud de dicho señor; he pasado a la casa de su habitación a reconocerle, y he encontrado lo siguiente: El Sr. Dn Teodosio Lares padece hace algunos ańos (según me han asegurado dos de los médicos que lo han asistido) una enteralgia crónica, o dolor nervioso en los intestinos, que se manifiesta dos o tres horas después de las comidas, y le produce un trastorno en las funciones de dichos órganos. Esta enfermedad, como todas las de naturaleza nerviosa, es muy anómala en su marcha, y también muy difícil de dominar; y aun cuando en el grado que hoy la tiene no se puede considerar mortal, no sería extraño llegase a tomar este carácter, no observando el método higiénico que hace más llevaderos estos males. Por ser cierto lo expuesto, lo certifico y juro.

Ignacio Erazo.

México, julio 28 de 1857.

Habiéndose reservado esta Sala en auto del 13 del pasado, proveer lo conveniente sobre el lugar donde debía sufrir su prisión el Sr. Dn. Teodosio Lares, con vista del resultado del reconocimiento de los facultativos, y no prestándole este mérito para dejar de hacerla efectiva; los documentos relativos a destierros, de que se trata en la parte final del auto anterior y aunque se refiere el Sr. Fiscal el pedimento citado en el mismo auto. 
La Secretaria de la $1^{\text {a }}$ Sala pasó a esta de la $2^{\text {a }}$ en mayo último, varios documentos, en diversos legajos, de actos ejercidos en la época del gobierno que emanó de los Tratados de Arroyo zarco; y en el examen que el que suscribe practicó de esos documentos para dar cuenta, notó que había varios que no pertenecían a causas pendientes ante la Excelentísima $2^{\text {a }}$ Sala, manifestándolo a los señores de ella; y se determinó que en lo particular volviesen a la $1^{\text {a }}$ Secretaría dichos documentos porque haciendo la separación debida, vinieran a está los que le correspondiesen.

Se hizo devolución y se anotó en el libro de conocimientos de la Secretaria de la $1^{\text {a }}$ Sala como correspondía y hasta hoy no se han recibido los documentos.

Esta es la razón por la que como se ha dicho, no puede cumplirse por ahora con lo dispuesto en la última parte del auto que antecede lo que asiento para dar cuenta.

Secretario Aguilar.

México, agosto 26 de 1857.

Con fecha 26 del actual se sirvió acordar el Sr. Ministro Semanero de la Excelentísima 2a Sala de esta Suprema Corte de Justicia se pidan a la Secretaria de la $1^{\text {a }}$ Sala, todos los documentos relativos a destierros que se encuentran firmados por el Sr. Dn. Teodosio Lares. México agosto 27 de 1857.

Con esta fecha, está Excelentísima 2a Sala se ha servido acordar se pida a la Secretaría del Tribunal Pleno, un certificado de las constancias que hubiere sobre si el Sr. Lares tomó posesión de la Magistratura, o si funcionó como tal Magistrado.

México, agosto 24 de 1857.

El día 8 de agosto último cerca de las cuatro de la tarde fuimos llamados del Ministerio de Justicia el Sr. Inspector del fondo Dn. Mariano Domínguez y el que suscribe como Tesorero. Yo ocurrí al llamamiento pero el Sr. Domínguez no hizo lo mismo por hallarse fuera de la capital, disfrutando de la licencia temporal que por enfermedad tuvo a bien concederle el Supremo Tribunal de Justicia de 
la Nación en uso de sus facultades. Llegando al Ministerio, me encontré en la sala de recibir con el Sr. Ministro Dn. Teodosio Lares, quien desde luego me manifestó la necesidad que tenía el Supremo Gobierno de que por la Tesorería del Fondo Judicial se ministraren 18 mil pesos, para un gasto de suma importancia: mi contestación fue la que en semejantes casos había dado al Sr. Ministro, que no tenía cantidad alguna disponible, ni posibilidad de adquirirla, porque acababa de distribuir las sumas colectadas al principio del mes, en el pago de sueldos de los Magistrados, jueces y empleados de los Tribunales y Juzgados del distrito correspondiente al mes de julio, entonces el citado Sr. Ministro me preguntó si el Tesorero de Instrucción Pública había enterado lo que adeudaba al fondo de administración de justicia, y como mi respuesta fue negativa, me hizo entrar a su despacho con el fin de esperar al Sr. Inspector Dn. José Urbano Fonseca, que también fue llamado por su S.E., llegó aquel a pocos momentos e impuesto del negocio por el Sr. Lares, recibió de éste orden para que entregase inmediatamente en la Tesorería del Fondo Judicial las cantidades que tuviera en caja, porque el Supremo Gobierno las necesitaba con urgencia. El Sr. Fonseca se separó en el acto para dar cumplimiento a las prevenciones que se le hicieron en mi presencia, y yo me retire a esperar el dinero y las órdenes que debían disponer la entrega de la esperada suma, y manifestando previamente que el Sr. Domínguez no estaba en la capital, y que siendo el conducto de comunicación, era preciso mandárselos para su conocimiento; el referido Sr. Ministro me dijo que el negocio no admitía demora de ningún género; urgido en la misma tarde por la entrega de la suma mencionada, no la verifiqué porque no la tenía, y porque aún no recibía las órdenes en las cuales debía explicarse su objeto, y la oficina o persona que estaba encargada de recibirla. El día 9 por la mañana a primera hora que fui llamado por el Sr. Ministro de Justicia, recibí de su propia mano la orden que aparece copiada en el expediente, y otra igual firmada por el Sr. Lares en favor del Sr. Dn. Ignacio Aguilar, e instruido de ambas hice al Sr. Ministro las observaciones convenientes, exponiéndole las dificultades que me ocurrieron para llevar los deseos del Supremo Gobierno, y S. E. me contestó, que los términos en que están 
concebidas las órdenes, me relevaban de toda responsabilidad, si alguna pudiera tener, y me previno de nuevo las cumplimentara sin dilación ni obstáculo. Apenas había llegado a mi oficina cuando se me presentó un enviado del Sr. Lares para recibir los nueve mil pesos que le correspondían, y le fueron entregados mediante el recibo que se ve copiado en la comunicación del Ministerio, que ha dado lugar a este informe, con la suma que existía en caja, y en la que al mismo tiempo enteró en la Tesorería a mi cargo el tesorero del Fondo de Instrucción Pública. El día 13 del citado mes de agosto que concurrió al Tribunal el Sr. Inspector, le di cuenta con lo ocurrido, le presenté las órdenes y le manifesté que había sido cumplida la relativa al Sr. Lares por las razones expuestas, y por la prevención que hizo al que informa al ausentarse de la capital, de obsequiar las disposiciones del Supremo Gobierno que tuvieren el carácter de urgentes, a reserva de ponerlas en su conocimiento cuando asistiera al despacho del Tribunal y así quedó concluido el negocio. He aquí los hechos que ocurrieron para la entrega de los nueve mil pesos que por orden del Supremo Gobierno recibió el Sr. Dn. Teodosio Lares, y con su relación cumplido el precepto de $\mathrm{V}$. E.

Pablo Vergara.

México noviembre 3 de 1855. Es copia. México, agosto 29 de 1857, y que se agrega conforme a lo prevenido por el Sr. Ministro Semanero en el Supremo auto de 22 del presente. Eulogio Barrera, oficial.

Dada cuenta que el Excelentísimo Sr. Presidente sustituto con el oficio de V. E. de 11 del actual, en que se me transcribió el del Sr. Ministro en turno de la Suprema Corte de Justicia, pidiendo que el gobierno designe el lugar que se crea a propósito para que en él sufra su prisión el Sr. Dn. Teodosio Lares, porque aquel Tribunal no tiene ninguno en que puedan estar reos de esta clase. S. E. se ha servido resolver: que la Suprema Corte de Justicia puede resolver lo que a bien tenga, en la inteligencia que se ponen a su disposición todos los locales dependientes del Supremo Gobierno. Lo que me honro en comunicar a V. E.

García.

México, agosto 19 de 1857. 
Con calidad de reserva, líbrese oficio al Exmo. Sr. Dn. José María de Lacunza, para que en contestación se sirva decir si podrá proporcionar en el Colegio de San Juan de Letrán una pieza en la que se conserve, en clase de preso, el Sr. Dn. Teodosio Lares.

Arrioja. Covarrubias. Ahumada.

México, agosto 26 de 1857.

En contestación al oficio de V.S. de ayer, relativo a que le manifieste si hay alguna pieza en este Colegio en qué conservar al Sr. Dn. Teodosio Lares, tengo el honor de manifestarle que podrá proporcionarse una para recibirlo, mediante orden del Supremo Gobierno, de quien inmediatamente depende este establecimiento. Reitero a V. S. las protestas de mi particular aprecio y respetuosa consideración.

José María Lacunza.

México, agosto 27 de 1857.

Líbrese comunicación al Superior Gobierno con inserción de la que antecede, para que si por su parte no hay inconveniente, se sirva expedir orden al Sr. Rector del Colegio de San Juan de Letrán, a fin de que pueda parar allí en calidad de preso Dn. Teodosio Lares, por haberle señalado esta Sala ese lugar.

Miguel Arrioja.

México, agosto de 1857.

El Fiscal dice que puesta ya en observancia la Constitución desde el 16 del presente, conforme al artículo transitorio con que la misma termina, V. E. se ve en la necesidad de arreglarse en el desempeńo de sus obligaciones y facultades, a los preceptos que ella contiene. Entre éstos se encuentra el del artículo 105 en que hablando de los delitos oficiales cometidos por los altos funcionarios, previene que conozca de ellos el Congreso como Jurado de Acusación, y la Suprema Corte de Justicia como Juzgado de Sentencia; pero este respetable cuerpo no ha de proceder como hasta aquí, por medio de Salas y de instancias diversas, sino en Tribunal Pleno y limitándose a declarar por una sola sentencia la pena que corresponde por la ley al funcionario que haya declarado culpable el Soberano Congreso; de 
manera que, extinguidos en estos casos los Tribunales de $1^{\mathrm{a}}, 2^{\mathrm{a}}$ y $3^{\mathrm{a}}$ instancia, en que estaba dividida la Suprema Corte de Justicia, ésta debe ejercer la facultad que siempre ha tenido de juzgar a los altos funcionarios de la nación en Tribunal Pleno.

Aplicando estas disposiciones a la presente causa, es indudable que V. E. no tiene jurisdicción para continuar conociendo de ella, porque siendo contra un Secretario del Despacho y oficiales los delitos por que se forma, como que consistieron en faltas y omisiones cometidas en el ejercicio de su encargo, que es como el artículo 130 de la Constitución define esa clase de delitos, claro es que en virtud de lo dispuesto en el artículo 105 antes citado, deben conocer el Soberano Congreso como Jurado de Acusación, y el Tribunal Pleno de la Suprema Corte de Justicia como Jurado de Sentencia.

En virtud de lo expuesto, el Fiscal pide a V. E. que con las formalidades que tenga a bien decretar, se sirva declararse incompetente en el conocimiento de esta causa y mandarla elevar al Soberano Congreso, que es quien inmediatamente debe continuarlo según su estado, dando V. E. sus disposiciones para que el reo quede a la de la sección del Gran Jurado de aquella Corporación Soberana.

México, septiembre 24 de 1857.

Vistos con arreglo a lo dispuesto en el artículo transitorio de la Constitución, se declara esta Segunda Sala incompetente para conocer de la presente causa, instruida en virtud de la Ley del 9 de enero de 1856. Póngase en conocimiento del Supremo Gobierno remitiéndole copia certificada de este auto.

Covarrubias. Lerdo de Tejada. Terán.

México, octubre 22 de 1857.

Ministro de Justicia, Negocios Eclesiásticos e Instrucción Pública: Hoy se transcribe al Soberano Congreso de la Unión, la nota de V. S. del 22 del actual, que contiene al auto expedido por la Segunda Sala de esa Suprema Corte de Justicia, en la causa de responsabilidad contra el Lic. Dn. Teodosio Lares por sus actos como Ministro de Justicia en la administración de Dn. Antonio López de Santa Anna, a fin de que el Congreso declare, si lo tiene a bien, quién es el Juez 
que deba conocer de las causas de responsabilidad de que habla el decreto del 9 de enero del ańo próximo pasado. Lo que digo a V. S. en contestación. Dios y Libertad.

Covarrubias.

México, octubre 29 de 1857.

\section{Documento II}

Suprema Corte de Justicia. Año de 1856. Juicio de responsabilidad contra quien corresponda, por la orden de 23 de junio de 1853 del Gobierno Dictatorial que despojó al Ayuntamiento de Veracruz de

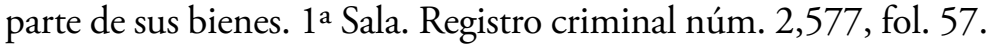
Toca a la causa del Sr. Dn. Teodosio Lares. Cuaderno núm. 2. Registro criminal de la $2^{\mathrm{a}}$. Sala, número 9 , folio 23.

El ciudadano Ignacio Comonfort, Presidente sustituto de la República Mexicana, a los habitantes de ella, sabed: que el Congreso Extraordinario Constituyente ha decretado lo que sigue: El Congreso Extraordinario Constituyente, en uso de la facultad que tiene para revisar los actos del Ejecutivo, declara lo siguiente: Es nula la orden expedida por el gobierno dictatorial de Santa Anna en 23 de junio de 1853, que despojó al Ayuntamiento de Veracruz de parte de sus bienes. En consecuencia quedan expeditos los derechos del despojado para la indemnización de los daños y perjuicios que haya sufrido por el despojo, así como incurso en responsabilidad el Ministerio que autorizó dicha orden.

Valentín Gómez Farías, Vicepresidente.

México, 2 de junio de 1856.

El Excelentísimo Sr. Presidente de la República se ha servido disponer, que V. E. haga que el Ayuntamiento de esa ciudad devuelva a sus respectivos dueños los locales de los oficios públicos del gobierno, que fueron de Dn. Ángel Santa Anna y de Figueroa y Cardeña; cuidando ese gobierno, de que el Ayuntamiento indemnice en justicia a los interesados por los dańos y perjuicios que reclaman. Lares. 
Dios y Libertad, México, Junio 23 de 1853.

Es copia que certifico. México, septiembre 9 de 1857.

El Ayuntamiento de esta ciudad acordó en el año de 1849 que por los locales bajos del Palacio Municipal se exigiera a los escribanos que los ocupaban con sus oficinas desde tiempo atrás (por haber pertenecido al cabildo y al gobierno de la Provincia), un arrendamiento de 15 pesos mensuales. Los escribanos, aunque disgustados de que no se les continuara el favor de dejárselos ocupar sin estipendio alguno, no pudiendo negar ni disputar siquiera el derecho del común sobre sus propias fábricas, se avinieron al pago y lo verificaron por algún tiempo. Luego que llegó y se encargó de la Presidencia de la República el General Santa Anna, interesado en uno de los oficios, dictó una orden de despojo contra el cuerpo municipal, y mandó que éste devolviera lo que había recibido por arrendamiento a los dueños o encargados de los propios oficios, pagara además daños y perjuicios, y entregara los locales a éstos, a quienes parece que declara propietarios de esa parte de la Casa Consistorial, según el tenor de esa orden.

Ésta que acompaño a U. en copia, es uno de los actos más odiosos de ese gobernante, no sólo por la expropiación inicua que causó, sino porque esa expropiación y esa iniquidad redundaron en provecho del Dictador. El Ayuntamiento tuvo que pagar una fuerte suma y resignarse a que desconociéndose todos sus derechos, y atropellándose la justicia, se le tratara como a usurpador para especular con las propiedades y fondos públicos.

Yo ruego a U. que pida con instancia en el seno del Soberano Congreso, a que dignamente pertenece, la revisión de este acto escandaloso que ha perjudicado grandemente a este común y que sigue perjudicándole.

Manuel G. Zamora.

Soy de U. afectísimo amigo y seguro servidor que besa su mano. Veracruz, mayo 9 de 1856.

Apoyados en estos antecedentes pasamos a examinar la orden de 23 de junio de 1853. Es deber de todo gobierno acatar las garantías 
individuales de los asociados; pero no se cumplirá jamás con tan sagrado deber, si los derechos del hombre y del ciudadano no se buscan en la senda de la justicia administrada con pureza, sostenida con las fórmulas y pronunciada con independencia.

El gobierno español no desconoció la verdad de ese principio, cuando organizó Tribunales para dirimir las contiendas de sus súbditos marcándoles la base de sus obligaciones, fijándoles sus cualidades, constituyendo en responsabilidad, e imponiendo el precepto general, de que ninguna persona podía ser condenada, ni despojada de sus bienes y acciones sin ser antes oída y citada en juicio; de manera que, para cerrar la puerta a todo abuso en esta materia, previno que aun sus mismos mandatos se obedecieran sin darles cumplimiento, siempre que estuvieran en desacuerdo con las máximas que van expuestas.

El gobierno dictatorial de Santa Anna, no obstante su poder arbitrario, protestó ante la nación, el poder y respeto a la justicia, y por eso estableció jueces, ante quienes los habitantes de la República entablaran sus querellas: les designó sus facultades, les fijó las reglas de los juicios y los casos de responsabilidad.

Rompiendo, pues, estas solemnes garantías, dictó la orden de 23 de junio de 1853, en cuya virtud falló indebidamente en lo relativo al domino que alegaba tener el Ayuntamiento de Veracruz, sobre los locales de su casa municipal que daba en arrendamiento; condenándolo también a la devolución de las rentas que él había percibido, y al resarcimiento de los perjuicios que los inquilinos le exigieran.

Con este procedimiento despótico invadió escandalosamente las facultades del Poder Judicial, atropelló el derecho de propiedad de que estaba en posesión el Ayuntamiento referido, arrebatándoselo sin ser oído ni citado en juicio; se constituyó ilegalmente en juez, sentenciando un negocio en que estaba interesado como parte; y en fin, con ese procedimiento conculcó los principios fundamentales del orden público, de la moral y de la justicia.

De aquí es que, la Comisión, para reivindicar los derechos ultrajados en este caso, para satisfacer a la opinión general que ha puesto toda su esperanza en la revisión que V. S. debe hacer de los actos de la administración que acaba de ser derrocada, sujeta a la delibera- 
ción del Soberano Congreso la siguiente proposición: Se declara nula la orden expedida por el gobierno dictatorial de Santa Anna de 23 de junio de 1853, que despojó al Ayuntamiento de Veracruz de parte de sus bienes, quedando en consecuencia expeditos los derechos del despojado para la indemnización de los daños y perjuicios que haya sufrido por el despojo, así como incurso en responsabilidad el Ministerio que autorizó dicha orden. México, junio 19 de 1856.

La atenta comunicación de U. fechada el 4 del corriente, ha impuesto al que suscribe, de que el Excelentísimo Ayuntamiento de esta ciudad, le ha ordenado, en virtud del decreto del Soberano Congreso de la nación, fechado el 19 de junio del último, que deroga la orden dada por el Sr. Gral. Santa Anna en 23 de junio de 1853, que exija U. a los dueños de los oficios públicos, o las personas que los representan, las cantidades que percibieron en virtud de la orden citada y los réditos correspondientes.

El que suscribe ha tenido a la vista el decreto del Soberano Congreso en virtud del cual se exige la citada devolución; y si bien esta disposición deja al Excelentísimo Ayuntamiento su derecho para reclamar los daños y perjuicios que pueda haber resentido, bajo ningún concepto encuentra que pueda dirigir su acción contra los dueños de los oficios públicos, sino contra los responsables de la referida orden.

En tal virtud, el que suscribe, en respuesta de la expresada nota de U. manifiesta que no está conforme, ni debe devolver cantidad alguna en su concepto, pues no cree que el Excelentísimo Ayuntamiento de esta ciudad, tiene ese derecho contra los dueños de los oficios públicos, en virtud del mencionado decreto.

Miguel A. Valdés, dueño de oficio público.

Veracruz, julio 7 de 1856.

Como el Excelentísimo Ayuntamiento desea proceder con acierto en todos sus actos, acordó en sesión extraordinaria celebrada hoy, consultar el Excelentísimo Señor Gobernador del Estado por el respetable conducto de V. S. si su acción para la devolución de las 
cantidades que satisfizo por indemnizaciones, y las que procedan de arrendamientos vencidos, debe entablarla contra los dueños de los oficios públicos o contra el Magistrado que expidió la orden. H. Ayuntamiento.

Veracruz, julio 8 de 1856.

Me cabe la honra de trasladarlo a V. E. para que con vista en el supremo decreto que se menciona, y lo que se manifiesta en la preinserta comunicación, se digne V. E. resolver lo que crea más acertado, para que el Excelentísimo Ayuntamiento de esta capital pueda proceder. Y tengo la honra de trasladarlo a V. E. para que sirviéndose dar conocimiento al Soberano Congreso, se digne tomar en consideración la duda que se consulta y resolver como interpretación del decreto relativo, si los escribanos que han ocupado y ocupan los locales, son los responsables a los arrendamientos que dejaron de cubrir en virtud de la orden anulada, y a las cantidades que les fueron devueltas por el Excelentísimo Ayuntamiento. $\mathrm{O}$ si éste debe dirigir su acción contra el autor o responsable de aquella providencia.

Llave. Gobernador.

Veracruz, julio 12 de 1856.

El Ayuntamiento de Veracruz solicita que V. S. aclare la resolución que dio, al revisar la orden expedida por Santa Anna, en 23 de junio de 1853, la cual despojó a dicha corporación de parte de sus bienes. La duda que se presenta es, si los escribanos que han ocupado los locales del Palacio Municipal en virtud de la orden de Santa Anna, son responsables a la devolución del importe de los arrendamientos vencidos, y a la de las cantidades que les fueron devueltas por tal providencia, o si la acción para todo lo dicho debe dirigirse al Ministro que autorizó dicho mandato.

La Comisión encargada de dictaminar en este asunto, juzga ajeno de las facultades de esta Asamblea semejante declaración. Declarada nula la orden de 23 de junio citada, considerada igualmente como un verdadero despojo, responsable al funcionario que la autorizó, y habiéndose dejado expeditos los derechos del despojado para 
la indemnización de lo pagado, y para percibir lo exhibido y perjuicios causados, nada tiene ya que hacer V. S. sino la autoridad judicial a quien corresponde llevar a cabo las consecuencias de la nulidad de la orden de que se trata y las que produce la indemnización que se deja a salvo al despojado; así es que, por todo lo dicho, los individuos de la Segunda Comisión de Gobernación, sujetan a la deliberación de V. E. la siguiente proposición: No es de las atribuciones del Soberano Congreso Constituyente, la aclaración que el Ayuntamiento de Veracruz solicita sobre la resolución que se dio al revisar la orden de 23 de junio de 1853, debiendo en consecuencia archivarse este expediente.

Soberano Congreso Extraordinario Constituyente. Segunda Comisión de Gobernación.

México, octubre 23 de 1856.

Para las causas criminales que se sigan en todos los Tribunales y Juzgados de la nación. México, junio 27 de 1857. 